\title{
Armine Kotin Mortimer et Katherine Kolb, (eds.) Proust in Perspective: Visions and Revisions
}

\section{Geneviève Henrot Sostero}

\section{(2) OpenEdition}

12 Journals

\section{Edizione digitale}

URL: http://journals.openedition.org/studifrancesi/36608

DOI: 10.4000/studifrancesi.36608

ISSN: 2421-5856

\section{Editore}

Rosenberg \& Sellier

\section{Edizione cartacea}

Data di pubblicazione: 1 juillet 2005

Paginazione: 195

ISSN: 0039-2944

\section{Notizia bibliografica digitale}

Geneviève Henrot Sostero, «Armine Kotin Mortimer et Katherine Kolb, (eds.) Proust in Perspective: Visions and Revisions», Studi Francesi [Online], 145 (XLIX | I) | 2005, online dal 30 novembre 2015, consultato il 18 avril 2021. URL: http://journals.openedition.org/studifrancesi/36608 ; DOI: https:// doi.org/10.4000/studifrancesi.36608

Questo documento è stato generato automaticamente il 18 avril 2021.

\section{(c) (1)}

Studi Francesi è distribuita con Licenza Creative Commons Attribuzione - Non commerciale - Non opere derivate 4.0 Internazionale. 


\title{
Armine Kotin Mortimer et Katherine Kolb, (eds.) Proust in Perspective: Visions and Revisions
}

\author{
Geneviève Henrot Sostero
}

\section{NOTIZIA}

ARMINE KOTIN MORTIMER et Katherine Kolb, (eds.) Proust in Perspective: Visions and Revisions, Urbana-Champaing, University of Illinois Press (USA), 2002, pp. 316.

Dedicato alla memoria di Philip Kolb, che ci ha procurato una monumentale edizione della corrispondenza di Proust e ha fondato il Centro degli Archivi Kolb-Proust all'Università dell'Illinois (Urbana-Champaing), il presente libro raccoglie gli atti del convegno internazionale tenutosi a Urbana nell'aprile 2000. Diviso in quattro parti, "Writing the Recherche", "The Knowledge of Words", "The Words of Art" e "Re-writing the Recherche", l'opera illustra il ventaglio degli approcci critici attualmente prediletti dagli specialisti dell'opera proustiana. Dai più informati studi storico-biografici nella scia di Philip Kolb (Luce FRAISSE, Philip Kolb behind the Scene of the 'Recherche', pp. 19-31), al più estroso dialogo immaginario tra cinque personaggi (Roger sHATTUCK, Ockham's Rasor and Proust's Beard, pp. 281-292), fino alla nozione di "biotesto" applicata alla Recherche (Joshua GIDDING, Hyperproust: The 'Recherche' as Hypertext, pp. 271-280), gli articoli aprono anche varchi insospettabili sull'archeologia genetica dell'opera: fonti, modelli, scelte generiche, riscritture interessano Chritin CANo (Death as Editor pp. 45-56), Nathalie MAURIAC DYER (Genesis of Proust's 'Ruine of Venise', pp. 67-84), nonché il compianto Anthony, PUGH, pioniere genetico, specialista dei manoscritti proustiani fino al 1914 (The Ending of 'Du côté de chez Swann', pp. 57-66). Altri reinterpretano personaggi minori in chiave allegorica come Dreyfus o Saniette anagramma di "sainteté" (Albert BerETTA ANGUISSOLA, Proust and Scapegoating: From Saniette to Dreyfus, pp. 85-102). 
2 La seconda sezione, dedicata al "Sapere delle parole", interroga grandi temi come l'amore e l'omosessualità, o la memoria involontaria. Vengono audacemente travolte le consuete letture del testo o di certi suoi episodi famosi, soprattutto nell'ambito del tema omosessuale: Lawren scheHR, Gaydar; A Proustian Anatomy of Cruising, pp. 172-185, Elizabeth LADENSON, Gilberte's Indecent Gesture, pp. 147-156, Volker Roloff, Desire, Imaginary, and Love: Erotic Readings of the 'Recherche', pp. 157-171. Il tema della memoria involontaria viene ridefinito in chiave stilistico-psicanalitica da Geneviève HENROT, che ne ridisegna una mappa radicalmente più estesa dei famosi motivi presenti nel Temps retrouvé, (Menmosyne and the Rustle of Language, pp. 105-115), mentre Christie MCDONALD rilegge la memoria da capo (Da capo: Accumulations and Explosions, pp. 116-132). Antoine COMPAGNON scioglie oscure allusioni culturali con la formula dell'ironia.

3 La terza sezione, "Le parole dell'Arte", accomuna pittura, musica e architettura in una riflessione ora stilistica (Françoise LERICHE, Proust: an 'Art Nouveau' Writer?, pp. 189-212), ora intertestuale (Diane LEONARD, Proust and Ruskin 2000: "ces étoiles éteintes dont la lumière nous arrive encore", ora fedele a una tradizionale ricerca storica delle fonti o delle allusioni: per Jérôme CORNETTE, il lied canticchiato da Robert de Saint-Loup non ha più segreti (“... un lied de Schumann": The Politics and Aesthetics of Singing, pp. 254-268); mentre Kazuyosh YoSHIKAWA conferma la sua specialità nell'identificare le fonti dei quadri proustiani (The Models of Miss Sacripant, pp. 240-253). Dotato di una bibliografia generale, di una biografia dei collaboratori e di un indice, il libro realizza l'incontro, raro quanto pregevole, tra critica europea e critica americana, attorno a un grande della letteratura francese. 